\title{
Cultura Inquisitória e as Falsas Oralidades
}

\author{
Inquisitorial Culture and the False Oralities
}

\author{
André Rocha Sampaio ${ }^{1}$ \\ Professor Adjunto de Direito Processual Penal do UNIT/AL - Maceió/AL \\ Doutor em Ciências Criminais pela PUCRS \\ andrerochasampaio@gmail.com \\ lattes.cnpq.br/0645556530168637 \\ ib orcid.org/0000-0002-6288-5487
}

Marcos Eugênio Vieira Melo

Mestrando em Ciências Criminais pela PUCRS - Porto Alegre/RS

marcos.evmelo@gmail.com

lattes.cnpq.br/6518709197337260

orcid.org/0000-0001-5854-579X

Resumo: O presente artigo tem como escopo evidenciar a necessidade da oralidade para superar a insuficiência das medidas que envolvem meras reformas legais para a modificação da cultura inquisitorial que nos aflige desde nossa matriz. Para tal, valemo-nos da hipótese de que a oralidade presente no modelo processual penal brasileiro é de baixa intensidade, enfraquecida pela lógica autoritária que atravessa nossa dinâmica processual desde fora. Foram utilizados diversos textos de processualistas penais nacionais e estrangeiros relacionados à necessidade de desvelamento do engodo do "sistema misto", da necessidade do direito ao confronto e da restauração da oralidade. Partiu-se

1 Professor das disciplinas Direito Processual Penal I e Direito Processual Penal II do Centro Universitário Tiradentes (UNIT/AL) e Direito Processual Penal I da Faculdade Integrada de Pernambuco (FACIPE/PE), Doutor em Ciências Criminais pela Pontifícia Universidade Católica do Rio Grande do Sul (PUCRS), Mestre em Direito pela Universidade Federal de Alagoas (UFAL), Pós-graduação Lato Sensu pela Escola Superior de Marketing de Alagoas (ESAMC/AL), Advogado.

2 Mestrando em Ciências Criminais pela Pontifícia Universidade Católica do Rio Grande do Sul (PUCRS), Pós-graduado em Processo Penal pelo Instituto Brasileiro de Ciências Criminais (IBCCRIM) e Faculdade de Direito de Coimbra, Advogado. 
de hipótese que uma oralidade em sentido forte não pode estar dissociada da imediação judicial e, sanando tal deficiência, a estrutura dialética do processo poderia ser mais bem evidenciada.

Palavras-Chave: inquisitoriedade; oral idade; confronto; imediação.

ABSTRACT: The purpose of this article is to demonstrate the necessity of orality to overcome the insufficiency of measures that concerns the very legal reforms to modify the inquisitorial culture that afflicts us from our matrix. For this, we have used the hypothesis that the orality found in the Brazilian penal process model is of a low intensity, weakened by the authoritarian logic that crosses our penal process dynamics from the outside. Various texts of national and foreign criminal proceduralists were used, mainly those related to the need to unveil the illusion of the "mixed system", the need for the right of confrontation and the restoration of orality. It was hypothesized that an orality in the strong sense cannot be dissociated from the judicial immediacy and, by remedying such deficiency, the dialectical structure of the process could be better evidenced. KEYwords: inquisitoriality; orality; confrontation; immediacy.

SUMÁRIo: Introdução; 1. Matrizes Inquisitoriais do Modelo Processual Penal Brasileiro; 2. A Oralidade como Elemento de Superação da Cultura Inquisitorial; 3. A Falsa Oralidade: estratégias de superação; Considerações Finais; Referências.

\section{INTRODUÇÃO}

O presente artigo aborda a necessidade de incremento da oralidade para superar a cultura inquisitorial que permeia o modelo processual penal brasileiro, muitas vezes refém de meras (insuficientes) modificações legislativas para tal. Este, que se apresenta como "acusatório", acaba por operar em uma lógica "inquisitorial reformada”, valendo-se do engodo da presença superficial de elementos dotados de democraticidade para obstar uma verdadeira ruptura de paradigma.

Trata-se de tema que adquire ainda maior relevo quando nos encontramos na iminência de um novo Código de Processo Penal, que corre o manifesto risco de preservar a nódoa inquisitória que atraves- 
sa nosso sistema desde seu nascedouro. Assim, buscaremos demonstrar que menos do que mudar leis se torna necessário repensar os fundamentos de operacionalização, tendo no trato da oralidade a pedra de toque.

Na consecução do presente, a literatura processual penal pátria de vanguarda, bem como diversos processualistas internacionais, serão utilizados como base para repensarmos o fenômeno por meio de breves comparativos com o direito estrangeiro. Nessa senda, a desconstrução do mito da acusatoriedade, traçada por Jacinto Nelson de Miranda Coutinho, e a necessidade de superação das falsas oralidades abordada por Alberto Binder constituem o referencial de base do presente.

O que temos, em suma, é um modelo que se reveste de certo verniz democrático, elencando, inclusive, como um dos princípios reitores a própria oralidade, mas que a rigor podemos questionar: trata-se de uma oralidade efetiva para a estruturação de um modelo que supere nosso ranço inquisitório? Partimos da premissa, então, de que essa oralidade frágil, divorciada da imediação judicial, contribui justamente para o oposto, a perpetuação do gérmen inquisitório, resistente a quaisquer modificações puramente legais, que não alcançam o âmago da cultura inquisitorial.

\section{Matrizes Inquisitoriais do Modelo Processual Penal Brasileiro}

Os sistemas jurídicos latino-americanos são, em grande parte, fruto da conjuntura política que os estruturou historicamente, nomeadamente no que tange aos conquistadores ibéricos. Desse modo, o cenário percebido hoje, resultado não de um determinismo absoluto, mas de um plexo de fatores estruturantes, contempla inexoravelmente uma forte tradição inquisitorial ${ }^{3}$, sinalizada por meio de, entre outros

3 Importante ter em questão que se deve entender o sistema inquisitivo não somente como um modo de organização do procedimento e da administração da justiça, mas que gera ao seu redor uma cultura inquisitiva que se retroalimenta ao longo do tempo e que o permitiu e permite sobreviver por esses quase quinhentos anos (BINDER, Alberto M. La justicia penal en la transición a la democracia en américa latina. Alicante: Biblioteca Virtual Miguel de Cervantes, 2005, p. 86). 
sintomas, uma extrema centralização hierárquica dos Tribunais e uma organização claramente burocrática. ${ }^{4}$

Por outro lado, sua dimensão político-criminal tem encontrado artifícios históricos discursivos para minar os aspectos limitadores do poder punitivo e fazer prevalecer elementos que ampliam o exercício do poder relacionado à persecução penal. Com efeito, tem-se que a relação entre o sistema político imperante e a substância do direito processual penal é mais direta e imediata do que em qualquer outro ramo do ordenamento jurídico. ${ }^{5}$

Já ensinava Goldschmidt que "os princípios de política processual de uma nação não são outra coisa que segmentos de sua política estatal geral”, bem como que "a estrutura do processo penal de uma nação não é senão o termômetro dos segmentos corporativos ou autoritários de sua constituição". ${ }^{6}$ Logo, entende-se que o fenômeno processual penal deve ser compreendido rizomaticamente, ${ }^{7}$ como elemento inserido

4 MAIER, Julio B. J. Situación de la justicia penal y problemas de los sistemas escritos. Revista de la Asociación de Ciencias Penales de Costa Rica, junio 1991, no 4, p. 2-3.

5 MAIER, Julio B. J. Derecho procesal penal. Tomo I: fundamentos. Buenos Aires: Del Puerto, 2006, p. 260.

6 GOLDSCHMIDT, James. Principios generales del proceso: problemas jurídicos y políticos del proceso penal. vol. II. Buenos Aires: Ediciones Jurídicas Europa-América, 1961, p. 110.

7 Deleuze e Guattari assim resumem os pontos principais de um rizoma: (1) ele conecta quaisquer dois pontos, cada um com suas características que não se remetem necessariamente a característica da mesma natureza, o rizoma põe em jogo regimes de signos muito distintos e até mesmo de não-signos; (2) Ele não se reduz nem ao Uno e nem ao Múltiplo; (3) ele não se compõe de unidades, mas de dimensões, ou, melhor, de direções que se modificam; (4) não tem nem início e nem fim, sempre um meio, no qual cresce e desborda; (5) o rizoma constitui multiplicidades lineares de n dimensões, sem sujeito ou objeto, distribuíveis em um plano de existência do qual sempre se subtrai o Uno (n-1); (6) ele é integralmente composto por linhas (de segmentariedade, de estratificação, de fuga ou desterritorialização, esta como dimensão máxima pela qual a multiplicidade se metamorfoseia ao mudar de natureza); (7) ele é uma anti-genealogia, uma memória curta ou anti-memória; (8) ele procede por variação, expansão, conquista, captura, injeção; (8) o rizoma está relacionado com um mapa que deve ser construído, produzido, sempre desmontável, conectável, alterável, com múltiplas entradas e saídas, em suas linhas de fuga; (9) trata-se de sistema acentrado, não hierárquico e não significante, sem um comando central, sem memória organizadora central (mais detalhes, 
em um contexto de circunvizinhança com os mais variados fatores - sociais, políticos, culturais, etc. - que o afetam ainda que indiretamente, produzindo irritações a serem observadas e interpretadas com base em seus próprios códigos. ${ }^{8}$ Desde uma perspectiva política, é necessário ressaltar que o papel do processo está inextrincavelmente relacionado com os desígnios do próprio Estado. ${ }^{9}$

Há, portanto, um nexo entre a manifestação política do Estado e o modo de exercício do processo. Em um Estado Democrático de Direito, no qual o cidadão tem seus direitos individuais protegidos, o processo tende à ampliação das garantias; já em um Estado em que a relação Estado-cidadão é desequilibrada e pende em favor exclusivamente do primeiro, as garantias são diminuídas ou eliminadas. ${ }^{10}$

Nessa senda, poder-se-ia esperar um modelo democrático de processo penal apenas de um Estado que de fato se pautasse por tais valores, todavia apenas se pautaria ele deste modo de possuísse instituições que estruturassem relações jurídicas deste jaez, fomentando, assim, uma relação bilateral complexa, de afetação recíproca, de modo que, ao se conceber o Estado como conjunto das manifestações políticas (lato sensu) de um determinado espaço geográfico, seria mais razoável operar uma reestrututação menos descendente do que ascendente (das instituições ao Estado). Neste sentido, Ferrajoli atribui ao direito e ao processo penal um caráter democrático apenas se servirem para limitar

cf. DELEUZE, Gilles; GUATTARI, Felix. Rizoma: introducción. Trad. José Vásquez Pérez e Umbelina Larraceleta. Valencia: Pre-textos, 2013, p. 48- 49).

8 LUHMANN, Niklas. O direito da sociedade. Trad. Saulo Krieger. São Paulo: Martins Fontes, 2016, p. 584.

9 GOMES FILHO, Antonio Magalhães. Direito à Prova no Processo Penal. Imprenta: São Paulo: Revista dos Tribunais, 1997, p. 18-19. Como adverte CHOUKR (Garantias constitucionais na investigação criminal. Rio de Janeiro: Lumen Juris, 2006, p. 8): “O Estado, pela sua óptica, cria uma regulamentação processual penal a partir dos valores políticos dominantes". Nessa ótica, para GIMENO SENDRA (Prólogo. In: GONZALES-CUELLAR SERRANO, Nicolas. Proporcionalidad y Derechos Fundamentales en el Proceso Penal. Madrid: Colex, 1990.p. 7), “o processo penal é, junto com o Direito Penal, o setor do ordenamento em que maiores poderes são concedidos ao Estado para a restrição dos direitos fundamentais que a Constituição reconhece aos cidadãos" (tradução livre).

10 BETTIOL, Giuseppe; BETTIOL, Rodolfo. Istituzioni di diritto e procedura penale. $7^{\mathrm{a}}$ ed. Pádua: CEDAM, 2000, p. 128-129. 
e diminuir a violência punitiva do Estado e assegure os direitos fundamentais do cidadão frente ao seu arbítrio e abuso da força ${ }^{11}$.

Dessa forma, no contexto especificamente brasileiro, a tendência inquisitorial do processo penal parte de uma matriz cultural portuguesa autoritária em que, por um lado, o julgador é o protagonista na produção das provas, bem como, por outro, a apologia ao punitivismo sob os mais variados discursos da pena e de seus populismos fazem com que se instale um impulso inquisitivo e uma mentalidade inquisitória nos diversos atores jurídicos. ${ }^{12}$

Com isso, entende-se que, assim como o sistema processual é reflexo do regime político ideológico, o sistema probatório é por sua vez a coluna vertebral do sistema processual. ${ }^{13}$ Logo, uma regulação normativa ou uma prática forense probatória que não respeite garantias constitucionais como a do contraditório, subvertem o sistema acusatório e convertem a decisão judicial em um exercício de pura arbitrariedade. ${ }^{14}$

11 FERRAJOLI, Luigi. Justicia penal y democracia. Jueces para la democracia, n. 4, Madrid, set. 1988, p. 3.

12 AMARAL, Augusto Jobim do. Política da prova e cultura punitiva: a governabilidade do processo penal brasileiro contemporâneo. São Paulo: Almedina, 2014, p. 389. Para mais detalhes sobre a matriz inquisitória/autoritária no sistema penal brasileiro, cf. BATISTA, Nilo. Matrizes ibéricas do sistema penal brasileiro. Rio de Janeiro: Revan: ICC, 2002, v. I. Esses discursos populistas/ inquisitórios acabam se revelando como o lugar em que existe a ligação mais genuína entre o desejo e o poder: "A linguagem da punição, mesmo podendo muito bem estar associada às melhores intenções, seduz profundamente, pois sabemos desde tempos que o discurso não é simplesmente aquilo que manifesta ou oculta o desejo, mas é o próprio desejo, traduz tão somente as lutas ou os sistemas de dominação, mas revela aquilo porque se luta, pelo que se luta - o poder, enfim, do qual queremos nos apoderar" (AMARAL, Augusto Jobim do; ROSA, Alexandre Morais da. Cultura da Punição: a ostentação do horror. Rio de Janeiro: Lumen Juris, 2014, p. 44).

GONZALEZ ALVAREZ, Daniel. La prueba en los procesos penales centroamericanos (Guatemala, El Salvador, Costa Rica. Revista de la Asociación de Ciencias Penales de Costa Rica, marzo 2000, n. 17, p. 1. Para MORA MORA (La prueba en el Codigo Procesal Penal Tipo para America Latina. Revista de la Asociación de Ciencias Penales de Costa Rica, junio 1992, n. 5, p. 53, tradução livre) "o sistema probatório adotado no processo penal constitui um termômetro do nível de desenvolvimento democrático de uma comunidade concreta”.

14 ESTRAMPES, Manuel Miranda. La prueba en los procesos penales acusatorios latinoamericanos, Actualidad Judicial. Revista del Poder Judicial del Estado de Zacatecas, núm.1, 2007, p. 39. 
Nessa conjuntura, o magistrado não pode estar envolvido com a produção de nenhum argumento, devendo se manter equidistante às partes, já que um juiz que formula a acusação, por exemplo, está "psicologicamente envolvido com uma das versões em jogo"15 e em um Estado Democrático de Direito não deve existir dúvida de que um juiz imparcial é requisito indispensável a um sistema processual-penal democrático. ${ }^{16}$

Um modelo processual inquisitivo, por outro lado, responde a uma concepção autoritária e antidemocrática, fazendo com que o processo penal perca sua condição de processo e se converta em um instrumento de opressão. ${ }^{17}$ Portanto, o processo penal deve se conceber como um sistema de garantias a todos frente a atuação punitiva do Estado. ${ }^{18}$

Atenta-se aqui que não se está a dizer que um denominado processo acusatório não poderá ser autoritário, pois basta que se tenha uma distribuição desigual de poderes processuais entre as partes para sê-lo, ${ }^{19}$ mas que em um modelo inquisitório em que o juiz tem a gestão da prova não poderá ser democrático. Igualmente, deve-se ter em apreço que a estrutura de um processo autoritário dispensa os atributos de acusatório ou inquisitório, ou ainda que categorias como democracia, direitos fundamentais e Constituição, comumente invo-

15 PRADO, Geraldo. Sistema Acusatório. 2. ed. Rio de Janeiro: Lumen Juris, 2001, p. 128.

16 STRECK, Lênio Luiz; OLIVEIRA, Rafael Tomaz de. O que é isto? - as garantias processuais penais? Porto Alegre: Livraria do Advogado Editora, 2012, p. 54.

17 Nesse sentido MONTERO AROCA (Principios del proceso penal: una explicación basada en la razón. Valencia: Tirant lo Blanch, 1997.pp. 28-29) chega a afirmar que: "El denominado proceso inquisitivo no fue $y$, obviamente, no puede ser, un verdadero proceso [...] El llamado proceso acusatorio sí es un verdadero proceso, por cuanto en él existe realmente un juez imparcial y dos partes parciales enfrentadas entre sí”.

18 ESTRAMPES, Manuel Miranda. La prueba en los procesos penales acusatorios latinoamericanos, Actualidad Judicial. Revista del Poder Judicial del Estado de Zacatecas, núm.1, 2007, p. 37. Nesse sentido, para PRADO (Sistema Acusatório. 2. ed. Rio de Janeiro: Lumen Juris, 2001, p. 45-47) o processo penal deve servir como uma função-garantia dos direitos fundamentais do acusado.

19 SCHUNEMANN, Bernd. La Reforma del Proceso Penal. Madrid: Dykinson, 2005, p. 35. 
cadas como bases de um sistema acusatório, não significam blindagem ao autoritarismo, justamente porque ele está para além dessas categorias e sistemas. ${ }^{20}$

Com efeito, importante apontar que as premissas de um processo penal democrático partem necessariamente de um instrumento de limitação de um poder punitivo estatal, "por ser o próprio exercício do poder o núcleo inquebrável de qualquer preocupação democrática”, ${ }^{21}$ tratando-se, portanto, do marco constitucional "como limite às derivas processuais de fundo autoritário, impondo um sistema processual que possa considerar-se ele mesmo um aparelho limite ao poder punitivo". ${ }^{22}$

Contudo, o reconhecimento às partes de um direito à prova permanece difícil e problemático nos sistemas processuais da Europa continental e seus derivados, muito em decorrência do peso da tradição inquisitória já mencionada e suas consequências: a figura do juiz na obtenção do material probatório, o dogma da verdade real, a preocupação com a economia processual e uma concepção peculiar do livre convencimento. ${ }^{23}$

Dessa forma, assim como a monarquia absolutista encontrou na inquisição o seu principal instrumento de controle, o Estado Moderno desenhou um novo modelo judicial, que contém todas as características do modelo inquisitorial, mas com outra roupagem. O século XX, por exemplo, manteve o sistema inquisitório vivo, o que se evidencia com o surgimento de governos ditatoriais em praticamente todos os países da América Latina. Porém, mesmo após o fim deste período histórico-político e a formalização da democracia, muitos países seguiram com seu modelo processual penal operando em um suposto "sistema misto",

20 GLOECKNER, Ricardo Jacobsen. Processo Penal Pós-acusatório? Ressignificações do Autoritarismo no Processo Penal. Revista EMERJ, Rio de Janeiro, v. 18, n. 67, p. 378-408, jan - fev. 2015, p. 389-398.

21 MELCHIOR, Antonio Pedro. O juiz e a prova: o sinthoma político do processo penal. Curitiba: Juruá, 2013, p. 146.

22 MARTINS, Rui Cunha. O Ponto Cego do Direito: The Brazilian Lessons. $3^{\text {a }}$ ed. São Paulo: Atlas, 2013, p. 74-75.

23 GOMES FILHO, Antonio Magalhães. Direito à Prova no Processo Penal. São Paulo: Revista dos Tribunais, 1997, p. 63. 
espelhado no Code Crimenelle bonapartista de $1808,{ }^{24}$ que nada mais é que um sistema inquisitório de aparência acusatória, uma espécie de "inquisitório reformado".

Emblemático deste modelo distópico é a adoção do princípio da instrumentalidade das formas, ou pas de nullité sans griefI, herança do aludido código napoleônico. De acordo com esse princípio, para o reconhecimento de determinada nulidade deverá a parte demonstrar a ocorrência de efetivo prejuízo, o que se torna espécie de "prova diabólica”, visto que demanda a demonstração de algo em uma dimensão temporal jamais plenamente realizada (o futuro do pretérito), uma espécie de prova do que aconteceria em uma linha de existência paralela na qual dado fato não veio a acontecer. O que se extrai como consequência disto é uma inelutável lesão ao arcabouço de garantias processuais, enfraquecidas com a relativização da forma que as protege, aumentando os poderes do julgador, que poderá manipular as formas sob o moldável fundamento da finalidade atingida, mascarando sutilmente um sistema sob a ótica inquisitória. ${ }^{25}$

É o que se vê no processo penal brasileiro, que desde a criação do seu código vigente, inspirado no código italiano da época fascista, não deixou dúvidas e nem precisou disfarçar que adotou o sistema inquisitório e que o juiz tinha a faculdade de produzir provas. ${ }^{26}$

24 BINDER, Alberto M. La fuerza de la Inquisición y la debilidad de la República. Política Criminal Bonaerense, n. 1, 2003.

25 GLOECKNER, Ricardo Jacobsen. Nulidades no Processo Penal: Introdução principiológica à teoria do ato processual irregular. Salvador: Juspudivm, 2015, p. 297-301.

26 "O projeto abandonou radicalmente o sistema chamado da certeza legal. Atribui ao juiz a faculdade de iniciativa de provas complementares ou supletivas, quer no curso da instrução criminal, quer a final, antes de proferir a sentença. (...) o juiz deixará de ser um espectador inerte da produção de provas. Sua intervenção na atividade processual é permitida, não somente para dirigir a marcha da ação penal e julgar a final, mas também para ordenar, de ofício, as provas que lhe parecerem úteis ao esclarecimento da verdade." (BRASIL, 1941). Ressalte-se que o principal idealizador do Código de Processo Penal de 1941 foi o Min. Francisco Campos, considerado um dos mais importantes intelectuais do autoritarismo brasileiro do século XX, que na Exposição de Motivos do Código de 1941 fez questão de citar o pensamento de Rocco e nunca escondeu sua influência no regime fascista italiano de Mussolini (MALAN, Diogo Rudge. Ideologia política de Francisco Campos: 
No entanto, após a Constituição de 1988, com a titularidade da ação penal pública privativa do Ministério Público e todas as garantias nela previstas, o imbróglio do senso comum teórico dos juristas ${ }^{27}$ passou a ser legitimar o sistema proposto pelo CPP mesmo de encontro com a própria Constituição. Foi então que se consagrou na doutrina nacional o famigerado "sistema misto".

Importante destacar que não há mais sistemas puros (se é que um dia existiu algum), todos são mistos, diferenciando-se para Coutinho quanto ao seu "princípio unificador", que poderá ser o dispositivo ou o inquisitivo. Com isso, quando um modelo tem em sua essência a produção da prova exclusivamente delegada às partes, terá como princípio unificador o dispositivo. Por sua vez, em modelos em que a gestão da prova fica a cargo do juiz (que é o caso brasileiro), terá como princípio unificador o inquisitivo:

Ora, faz-se uma opção política quando se dá a função de fazer aportar as provas ao processo seja ao juiz (como no Sistema Inquisitório), seja às partes, como no Sistema Acusatório, por evidente que sem se excluir (eis por que todos os sistemas são mistos) as atividades secundárias de um e de outros, tudo ao contrário do que se passava nos sistemas puros. Daí que a gestão da prova caracteriza, sobremaneira, o princípio unificador e, assim, o sistema adotado. ${ }^{28}$

Influência na legislação processual brasileira (1937-1941), In: MALAN, Diogo Rudge; PRADO, Geraldo (orgs.). Autoritarismo e processo penal, Rio de Janeiro: Lumen Juris, 2015, p. 46).

Entende-se como "senso comum teórico" o sentido empregado por Luiz Alberto Warat: "o 'senso comum teórico', diremos que ele representa um sistema de conhecimentos que organiza os dados da realidade, pretendendo assegurar a reprodução dos valores e práticas predominantes. Trata-se de um discurso que oferece respostas que apenas aludem ao real e comandadas por interesses que tomam a forma de princípios ou diretrizes. Assim, não é difícil ver que o senso comum teórico apresenta um conjunto de questões onde as respostas já são sobredeterminadas" (WARAT, Luiz A. O senso comum teórico dos juristas. Disponível em: <http://casadewaratportoalegre.blogspot.com. br/2011/04/o-senso-comum-teorico-dos-juristas-luiz.html>. Acesso em: 23 out. 2016).

28 COUTINHO, Jacinto Nelson de Miranda. Sistema Acusatório - Cada parte no lugar constitucionalmente demarcado. Revista de informação legislativa, Brasília, v. 46, nº 183, p. 103-115, jul./set. 2009, p. 109. 


\section{A Oralidade como Elemento de Superação da Cultura INQUISITORIAL}

Diferente dos demais países da américa latina o Brasil está remando em maré contrária em relação aos avanços democráticos no processo penal. Isso se dá porque desde o início da década de oitenta, com os primeiros países a abandonar as ditaduras militares e iniciar a transição democrática, começou um movimento de caráter regional denominado "movimento de reforma da justiça penal", que visava a fazer uma verdadeira revolução na legislação e especialmente na cultura jurídico-penal da região. Desde a década de 80 até os dias atuais 14 países reformaram integralmente seus Códigos de Processo Penal para adotar o princípio acusatório, contudo, distintamente, o Brasil continua com seu Código de Processo Penal da década de quarenta, que em sua essência é inquisitório e antidemocrático, bem como permanece sem esperança de uma grande alteração, já que o projeto que visa a substituí-lo passa por sérios riscos de permanência do gérmen da inquisitoriedade.

Tais reformas vêm ocorrendo após transformações das estruturas políticas dos países latino americanos em uma tentativa de consolidação da democracia, caracterizando-se pela tentativa de abandono dos modelos processuais penais inquisitivos ou mistos e a progressiva substituição por modelos acusatórios que estejam conforme suas constituições. ${ }^{29}$

Nessa tentativa de instalar uma mudança de mentalidade dentro do sistema de justiça criminal, a oralidade se põe como técnica importante para ocorrência de uma ruptura da tradição inquisitória. ${ }^{30}$ Não se trata de afirmar que o princípio democrático não tenha eficácia em um processo pautado pela forma escrita, ou que somente a oralidade possa estruturar um processo penal democrático ${ }^{31}$, mas de identificar

29 ESTRAMPES, Manuel Miranda. La prueba en los procesos penales acusatorios latinoamericanos, Actualidad Judicial. Revista del Poder Judicial del Estado de Zacatecas, núm.1, 2007, p. 40.

30 NUNES, Leandro Gornicki. Sistema Processual Penal adversarial: entre a democratização e o eficientismo penal. In: GOLZÁLEZ, L. (Dir.). Desafiando a Inquisição: Ideias e propostas para a Reforma Processual Penal no Brasil. Santiago: CEJA, 2017, p. 80.

31 No mesmo sentido MONTERO AROCA: "puede existir perfectmente un proceso con todas las garantías que sea escrito, como demuestra la historia. Una 
uma maior democraticidade à forma oral do procedimento, de modo que a decisão judicial se origine em um ambiente marcado pela dialeticidade e a efetiva contraposição de argumentos. ${ }^{32}$

Assim, desde já convém demarcar nosso lugar de fala, deixando claro que não defendemos aqui a oralidade como panaceia e nem sequer um processo penal totalmente oral, afinal, em conformidade com Cappelletti,

Examinando as provas escritas, e, mais genericamente, as provas ditas pré-constituídas, podemos desde logo constatar que a sua importância não foi menosprezada por nenhum ordenamento processual que soube aplicar com sucesso o princípio da oralidade. É certo que este princípio implica uma fundamental, prática e teoricamente, importantíssima revaloração da prova oral, mas esta revaloração não tem necessidade de vir acompanhada de uma irracional desvalorização da prova documental (pré-constituída). ${ }^{33}$

Superado esse ponto, convém ressaltar que sem um juízo verdadeiramente oral e público não se pode sequer começar a falar de como deixar a tradição inquisitória para trás, especialmente nos países da América Latina em que a mentalidade que dela se origina está arraigada por toda estrutura jurisdicional. ${ }^{34}$ Como bem sinaliza

cosa es afirmar la preferencia por la oralidad y otra negar a la escritura el pan y la sal" (El principio acusatorio entendido como eslogan político. Revista Brasileira de Direito Processual Penal, Porto Alegre, vol. 1, n. 1, p. 66-87, 2015, p. 70). No mesmo sentido Jordi Fenoll afirma que não se pode mais manter a ideia de que a oralidade soluciona todos os males do processo, mas, ao contrário, ela tem suas vantagens e desvantagens, no qual deve-se reconhecê-los e tentar melhorá-los para que o processo possa ser o mais democrático possível (Los problemas de la oralidad. Revista do Ministério Público do Rio Grande do Sul, Porto Alegre, n. 67, p. 237-257, set./dez., 2010, p. 247).

MAYA, André Machado. A oralidade como técnica de redução das práticas autoritárias no processo penal. Porto Alegre: PUCRS, 2015. 329 f. Tese (Doutorado em Ciências Criminais) - Programa de Pós-Graduação em Ciências Criminais, Faculdade de Direito, PUCRS, 2015, p. 224.

33 CAPPELLETTI, Mauro. O valor atual do princípio da oralidade. Revista da Faculdade de Direito da UFRGS, Porto Alegre, 2002, v. 21, p. 255-260, mar. 2002, p. 257.

34 BINDER, Alberto M. La fuerza de la Inquisición y la debilidad de la República. Política Criminal Bonaerense, n. 1, 2003, p. 12. 
Gonzalez Alvarez, ${ }^{35}$ a oralidade não constitui um princípio em si mesmo, mas um facilitador dos princípios políticos básicos e das garantias que estruturam o processo penal. Dessa forma, associa-se a oralidade a um projeto do constitucionalismo democrático chamado por Marinho Marques $^{36}$ de "movimento de superação do método inquisitivo", ao passo que aderir a um ambiente marcado pela oralidade seria incorporar na sentença e constituir a "base do raciocínio problemático que permite encontrar, na complexidade do Direito, a resposta adequada ao caso concreto". ${ }^{7}$

Por isso que tais países colocaram em suas reformas o juízo oral como eixo central no processo de produção de provas no processo penal, ${ }^{38}$ numa tentativa de afastar a mera reprodução burocratizada do que foi realizado na fase de investigação preliminar, que comumente ocorre nos sistemas inquisitórios ou mistos. Assim, "é nesse panorama do juízo oral em que se garantem em sua plenitude os princípios da oralidade, imediação, contraditório e publicidade" ${ }^{39}$ Importante salientar, todavia, que a implementação da oralidade não significa a exclusão da escrita, no

35 GONZÁLEZ ALVAREZ, Daniel. La oralidad como facilitadora de los fines, principios y garantías del proceso penal. Revista de Ciencias Penales, $\mathrm{n}^{\circ} 11$, Año 8, julio 1996. ABC Ediciones, p. 643.

36 MARINHO MARQUES, Leonardo. O princípio da oralidade como componente racional de gestão democrática do processo penal. Revista da Escola Nacional da Magistratura, Brasília, ano 06, n. 06, p. 506-520, 2012, p. 507.

37 Alerta Figueiredo Dias, contudo, que mesmo nos processos considerados mais inquisitórios não faltaram atos processuais orais entre o inquisidor, por um lado, e o acusado, as testemunhas, etc., por outro (Direito processual penal. v. 1. Coimbra: Coimbra, 1974, p. 230-231).

38 Como exemplo o art. 356.1 do CPP peruano em que afirma: "El juicio es la etapa principal del proceso. Se realiza sobre la base de la acusación. Sin perjuicio de las garantías procesales reconocidas por la Constitución y los Tratados de Derecho Internacional de Derechos Humanos aprobados y ratificados por el Perú, rigen especialmente la oralidad, la publicidad, la inmediación y la contradicción en la actuación probatoria. Asimismo, en su desarrollo se observan los principios de continuidad del juzgamiento, concentración de los actos del juicio, identidad física del juzgador y presencia obligatoria del imputado y su defensor".

39 ESTRAMPES, Manuel Miranda. La prueba en los procesos penales acusatorios latinoamericanos, Actualidad Judicial. Revista del Poder Judicial del Estado de Zacatecas, núm.1, 2007, p. 46, (tradução livre). 
sentido de que exista uma proibição de que os atos produzidos oralmente não possam ser registrados para fins de controle das provas. ${ }^{40}$

No entanto, passados quase 30 anos da refundação democrática e constitucional, o Brasil não tem perspectiva concreta de quando haverá um novo Código de Processo Penal e o sistema político local tem optado pela estratégia de promover reformas parciais no código vigente. Contudo, o que se mostrou com a experiência - nacional e dos outros países latinos - foi que essas reformas foram "rapidamente absorvidas e distorcidas pela lógica tradicional, porque não alteram a estrutura de serviços que atravessa os atores do sistema", pois quando se trata de lidar com sistemas fortemente arraigado em uma cultura inquisitorial "somente reformas radicais permitem lidar com os déficits de um desenho institucional ineficiente, para garantir direitos individuais e, ao mesmo tempo, adjudicar responsabilidades". ${ }^{41}$

Não se está tentando reduzir a reforma a um mero fetichismo legalista, pois cairia no erro de somente trocar um código por outro, mantendo-se uma cultura autoritária que continuaria com interpretações distorcidas das formas processuais. No entanto, seria muito difícil (senão impossível) haver uma transformação na justiça penal sem se modificar integralmente esta legislação, que é funcional à tradição inquisitorial. ${ }^{42}$

Sabe-se que o problema vai muito além da mera troca de legislações, perpassando também e principalmente por uma dimensão hermenêutica e cultural. Como se sabe a mentalidade inquisitiva continua até os dias atuais se travestindo das mais diversas roupagens e mitos processuais penais. ${ }^{43}$ Não por outro motivo, apareceram as chamadas "falsas oralidades", que serão melhor estudadas no próximo tópico.

40 FIGUEIREDO DIAS, Jorge. Direito processual penal. v. 1. Coimbra: Coimbra, 1974, pp. 230-231.

41 MELCHIOR, Antonio Pedro. Os movimentos de reforma do Código de Processo Criminal brasileiro. In: GOLZÁLEZ, L. (Dir.). Desafiando a Inquisição: Ideias e propostas para a Reforma Processual Penal no Brasil. Santiago: CEJA, 2017, pp. 50-51.

42 BINDER, Alberto M. La fuerza de la Inquisición y la debilidad de la República. Política Criminal Bonaerense, n. 1, 2003, p. 11.

43 Na perspectiva de CASARA (Mitologia processual penal. São Paulo: Saraiva, 2015 , p. 87) "por mitologia processual penal, tem-se o conjunto de mitos 


\section{A Falsa Oralidade: estratégias de superação}

Em Estados no qual o sistema processual penal está colonizado pela cultura inquisitória não se pode esperar uma mudança repentina no modo como os processos se operacionalizam. Essa mudança deverá ser firme, porém gradual, não somente na legislação processual, mas, sobretudo, na mentalidade e cultura presente.

Isso é facilmente percebido em solo brasileiro no que tange à legislação criminal, uma vez que as normas, ainda que modificadas, continuam sendo aplicadas por conduto de atitudes e interpretações mais bem caracterizadas pelo modelo anterior, operando uma certa perpetuação de valores anacrônicos nas fissuras da hermenêutica da nova redação. Dos vários exemplos que se têm, optou-se por mostrar um que já se tornou emblemático no processo penal brasileiro: trata-se o do artigo 212 do Código de Processo Penal brasileiro, modificado pela Lei 11.690/2008 numa tentativa de adequar a produção da prova testemunhal ao princípio dispositivo, dando diretamente às partes a possibilidade de perguntar as testemunhas. Porém, o que se constatou na prática foi que as perguntas continuaram a ser produzidas pelo julgador, mesmo indo de encontro ao que foi modificado pela legislação.

Não é diferente no que se trata da oralidade, que mesmo estando presente desde a redação original do Código de Processo Penal em 1941 sempre foi relegada pelos intérpretes para atender a certos desígnios punitivos. É nessa conjuntura que surgem as "falsas oralidades" que, segundo Binder seria quando "a oralidade não está a serviço da imediação: por exemplo, quando se realizam audiências públicas mas nelas não se produzem provas, de modo que o juiz que tem que tomar a decisão não tenha observado a prova diretamente ou já tenha sua opinião formada (pré-julgada)", ou ainda “vá a ler o que foi produzido na

penais que versam sobre a persecução penal (tanto a investigação preliminar como a persecutiocriminis in judicio); isto é, sobre a atividade estatal de investigar e punir aqueles a quem foi atribuída a prática de um delito. Trata-se de mitos que, como todos os outros, são dogmáticos, coletivos, ahistóricos e funcionalmente úteis ao sistema para o qual nascem e produzem seus efeitos". 
fase de investigação para tomar uma decisão independente do que se tenha feito em juízo". ${ }^{44}$

Não obstante, a imediação deve incidir na produção da prova que deve ser valorada pelo julgador na hora de decidir, a rigor impedindo o julgador ir atrás ou receber informações obtidas por outros que não as partes e/ou em outro momento senão na instrução probatória em contraditório. ${ }^{45}$

Para Massa, portanto, essa prática da falsa oralidade é considerada uma “farsa através da 'confirmação' de uma declaração já produzida, que em muitas vezes é a confirmação de uma confirmação feita em fase de instrução das declarações realizadas na delegacia”. ${ }^{46}$

Compartilhando deste pensamento, Alberto Binder escreve que:

O juiz que irá julgar o caso penal deve ser quem tem que ter a comunicação direta com as partes e quem observa diretamente a prova (...) esses juízos devem ser públicos, mas verdadeiramente públicos, de modo que a sociedade possa observar como seus juízes administram a justiça (...) esses juízos devem permitir a ampla defesa e isso se coloca mediante a concentração da prova - que permite discutir o valor dos elementos probatórios - e de uma estrutura verdadeiramente contraditória que permita discutir, ante o juiz, a melhor solução do caso. ${ }^{47}$

É preciso reconhecer que nosso sistema processual penal funciona através de uma conversão automática em prova dos elementos reunidos pela investigação. Com isso, na prática, as decisões são profe-

44 BINDER, Alberto M. La justicia penal en la transición a la democracia en américa latina. Alicante: Biblioteca Virtual Miguel de Cervantes, 2005, p. 99, tradução livre.

IBAÑEZ, Perfecto Andrés. Sobre el valor de la inmediación (Una aproximación crítica). Jueces para la democracia, n. 46, pp. 57-66, 2003, p. 58.

MASSA, Michele. Contributo all'analisi del giudizio penale di primo grado. Milano: Giuffrè, 1976, p. 278 (tradução livre).

47 BINDER, Alberto M. La justicia penal en la transición a la democracia en América Latina, In: BINDER, Alberto M. Política Criminal de la formulación a la praxis. Buenos Aires: AD-HOC S.R.L., 1997. Cap. XII, p.195-216, p. 214 (tradução livre). 
ridas quase que exclusivamente com base nesses elementos de investigação, e isso significa para Binder proferir sentenças inconstitucionais. ${ }^{48}$

Nessa senda, Aury Lopes Jr. adverte que

A fraude reside no fato de que a prova é colhida na inquisição do inquérito, sendo trazida integralmente para dentro do processo e, ao final, basta o belo discurso do julgador para imunizar a decisão. Esse discurso vem mascarado com as mais variadas fórmulas, do estilo: a prova do inquérito é corroborada pela prova judicializada; cotejando a prova policial com a judicializada; e assim todo um exercício imunizatório (ou, melhor, uma fraude de etiquetas) para justificar uma condenação, que, na verdade, está calcada nos elementos colhidos no segredo da inquisição. O processo acaba por converter-se em uma mera repetição ou encenação da primeira fase. ${ }^{49}$

Essa é, portanto, uma consequência do "sistema misto", que impede que o juízo se converta na etapa central do procedimento e torne-se uma etapa vazia de conteúdo e importância, uma vez que o que foi produzido na fase inquisitiva contamina todo o procedimento, transformando a investigação na principal etapa na formação das "provas", reduzindo ou eliminando a centralidade que deve revestir o juízo. ${ }^{50}$

Assim, um processo só poderá ser considerado verdadeiramente oral se a fundamentação da sentença for realizada exclusivamente mediante os fatos que foram produzidos oralmente em juízo. ${ }^{51}$ Claro que esse princípio não deve ser absoluto, pois no juízo oral poderão ser introduzidos certos elementos de provas já produzidos

48 BINDER, Alberto M. Introdução ao Direito Processual Penal. Rio de Janeiro: Lumen Juris, 2003, p. 182.

49 LOPES JR., Aury. Fundamentos do Processo Penal - Introdução Crítica. São Paulo: Saraiva, 2016, p. 162.

50 BOVINO, Alberto. Problemas del derecho procesal penal contemporáneo. Buenos Aires: Editores del Puerto, 1998, p. 6.

51 GIMENO SENDRA, Vicente. Derecho Procesal, t. II, vol. I. Valencia: Tirant lo Blanch, 1987, p. 90. "O julgamento é, portanto, o momento da prova, em um sentido básico” (BINDER, Alberto M. Introdução ao Direito Processual Penal. Rio de Janeiro: Lumen Juris, 2003, p. 181). 
anteriormente à fase judicial, exibindo-os ou através de leituras, quando imprescindível. ${ }^{52}$

Nesse aspecto, toma-se como parâmetro a análise do valor da "prova” produzida na fase preliminar, não podendo dar um valor unitário a todos os atos produzidos na fase de investigação, sendo suficiente distinguir as provas pré-constituídas e as provas constituendas. As primeiras seriam as fontes de conhecimento pré-existentes ao processo, como documentos ou outro tipo de prova perecíveis no tempo e, portanto, não repetíveis, enquanto as segundas têm sua produção no curso do processo decorrentes normalmente de fontes pessoais como, em regra, as testemunhas. ${ }^{53}$

Logo, esses atos produzidos na fase de investigação preliminar, mas com status de prova pré-constituída, são exceções ao binômio oralidade-imediação. Concordamos com Pedro Demerican no sentido dessas provas serem colocadas para valoração em uma fase pré-debate com um juiz diferente do que for julgar a causa, para que haja o contraditório e possa servir como um meio de preparação para a fase de debate, com o objetivo de não contaminar o magistrado competente para o julgamento da causa. ${ }^{54}$ Já no que tange às provas constituendas, estas devem seguir o trâmite da oralidade-imediação na fase judicial, para que o julgador a receba de forma direta e sem intermediários, exigindo-se a presença de todos os sujeitos processuais.

Assim, como as chamadas provas pessoais são os meios de prova mais usados, sobretudo em crimes mais tradicionalmente cooptados pelo sistema penal, e em grande parte dos processos os atos produzidos na investigação são o único embasamento do Ministério Público para

52 GONZÁLEZ ALVAREZ, Daniel. La oralidad como facilitadora de los fines, principios y garantías del proceso penal. Revista de Ciencias Penales, $\mathrm{n}^{\circ} 11$, Año 8, julio 1996. ABC Ediciones, p. 645. São imprescindíveis os atos anteriormente produzidos e irrepetíveis ou irrealizáveis durante a audiência de concentração, porém devem ser restritos e taxativamente previstos para não se tornarem corriqueiros.

53 BADARÓ, Gustavo Henrique. O valor probatório do inquérito policial. In: VASCONCELOS, Eneas Romero de; MALRINO, Ezequiel; AMBOS, Kai. Polícia e investigação no Brasil. $1^{\mathrm{a}}$ ed. Brasília: Gazeta Jurídica, 2016. p. 262-263.

54 DEMERICAN, Pedro H. A oralidade no processo penal brasileiro. São Paulo: Atlas, 1999, p. 51. 
denunciar ou não o investigado e, ao fim, após repetição na fase processual, para o juiz condená-lo ou absolvê-lo, acabam sendo a principal carga alucinatória do inquérito levada ao processo.

No mesmo sentido, no que tange ao processo penal alemão Schünemann: ${ }^{55}$

\begin{abstract}
Os autos da investigação são normalmente compostos em grande medida pelos registros (Protokolle) das inquirições de testemunhas feitas em sede policial. Como já demonstraram uma série de pesquisas sociológicas a respeito da inquirições policiais de testemunhas, o registro dessas inquirições não é de nenhuma forma idêntico a uma mera reprodução do quadro mnemônico da testemunha (comparável à descrição de uma fotografia), mas um verdadeiro produto da interação entre a testemunha e os funcionários públicos encarregados da inquirição e é, também, forte e massivamente influenciado pelas hipóteses formuladas pelo policial a respeito dos supostos contornos do acontecimento, hipóteses essas que orientam as perguntas.
\end{abstract}

Entende-se, portanto, que essa condição de validade probatória das provas produzidas na oralidade e imediação ficam restritas às provas pessoais. Há quem distinga, nessa senda, a participação do juiz na prova e participação do juiz sobre a prova: na primeira, o julgador participa na formação ou produção da prova chamada de testemunhal (v.g. testemunhas, vítimas) e das outras fontes de provas que forem produzidas durante o curso do processo judicial (provas constituendas). Por outro lado, a participação do juiz sobre a prova tem-se quando a prova já foi produzida, cabendo ao juiz a decisão sobre a possibilidade de sua admissão ou não. Assim, a imediação e a oralidade atingiriam apenas a participação do juiz na prova, ou seja, nas provas que sua produção se pretende ainda fazer. ${ }^{56}$

Tratando desse tema e introduzindo a questão do contraditório a partir da reforma do processo penal italiano, Ferrua aduz que no sistema

55 SCHUNEMANN, Bernd. Audiência de instrução e julgamento: modelo inquisitorial ou adverarial? Sobre a estrutura fundamental do processo penal no $3^{\circ}$ milênio. In: GRECO, Luís. Estudos de direito penal, direito processual penal e filosofia do direito. São Paulo: Marcial Pons, 2013.

56 GOMES, Décio Alonso. Prova e imediação no processo penal. Salvador: Juspodivm, 2016, p. 87. 
anterior ao código italiano de 1988 o contraditório era exercido essencialmente sobre as provas já produzidas, como nas atas dos depoimentos das declarações prestadas nos órgãos de investigação, enquanto no sistema após 1988 se realiza no exato momento de formação da prova, havendo uma separação entre a investigação preliminar e a fase de debates orais, no qual as provas são produzidas perante o juiz com contribuição direta das partes. Isso demonstra o que ele chama de regra de ouro do processo acusatório: as declarações das testemunhas somente valem como provas no processo se produzidas com o método do exame cruzado. ${ }^{57}$

Sob determinado aspecto, esse binômio oralidade-imediação aparece como uma modalidade de interação comunicacional, isto é, com a possibilidade de uma ativa interação entre as fontes e os meios de prova. Com isso, o sobredito binômio se torna um forte aliado da participação das partes em contraditório mediante a paridade de armas e o direito ao confronto. ${ }^{58}$

Daí tem-se a garantia do direito ao confronto no processo penal, cujo conceito é o de que "todo saber testemunhal incriminador passível de valoração pelo juiz seja produzido de forma pública, oral, na presença do julgador e do acusado e submetido a inquirição desse último", com isso, "a declaração de uma determinada testemunha não pode ser admitida como elemento de prova contra o acusado, a não ser que ela tenha sido prestada nas sobreditas condições". ${ }^{99}$ Dessa forma o direito de confrontar-se atrela-se à inutilizabilidade ${ }^{60}$ das declarações prestadas fora do âmbito do contraditório e do direito ao confronto. ${ }^{61}$

57 FERRUA, Paolo. Gênese da reforma constitucional do "giusto processo" na Itália. Revista Brasileira de Direito Processual Penal, Porto Alegre, vol. 3, n. 2, p. 661-688, mai./ago. 2017, p. 664-665.

58 GOMES, Décio Alonso. Prova e imediação no processo penal. Salvador: Juspodivm, 2016, p. 93.

59 MALAN, Diogo Rudge. Direito ao confronto no processo penal. Rio de Janeiro: Lumen Juris, 2009, p. 78.

60 Considera-se a inutilizabilidade um tipo de invalidade que atinge não o ato em si, mas o seu valor probatório. $\mathrm{O}$ ato pode ser considerado válido do ponto de vista formal, mas o seu aspecto substancial o impede de servir de fundamentação para a decisão do juiz (TONINI, Paolo. A prova no processo penal italiano. São Paulo: Revista dos Tribunais, 2002, p. 27).

61 TONINI, Paolo. A prova no processo penal italiano. São Paulo: Revista dos Tribunais, 2002, p. 29. 
Assim, a necessidade de produção probatória que atenda a essas garantias judiciais acarreta uma obrigatoriedade de exclusão do material probatório que não atenda a essas particularidades. Lembra Scarance Fernandes ${ }^{62}$ que no Brasil, onde a realidade coloca o inquérito instruindo a denúncia e acompanhando o processo, a leitura de atos produzidos na fase preliminar não são debatidos ou efetivamente confrontados, porém são utilizados de forma deliberada para fundamentar as decisões dos julgadores.

Adverte Binder que somente as provas verdadeiramente orais devem satisfazer essas exigências democráticas, não podendo contar as falsas oralidades, que seria quando a oralidade não estivesse a serviço da imediação. Assim, resumindo o que ele chama de sistema baseado na ideia de centralidade do juízo:

Deve-se assegurar uma verdadeira preservação do princípio da imediação, limitando a incorporação da prova por leitura, estruturando corretamente os recursos de modo a que o juízo não se volte a escrituralizar por via indireta: deve-se estabelecer um sistema de deliberação da imediação para que o juiz deva construir seu convencimento 'unicamente através do debate' e não se funde na fase prévia. (...) Deve-se, ainda, assegurar uma etapa preparatória ao juízo que não 'contamine o juiz' e que acabe com a tradicional força do 'inquérito'. Tem-se que ter em conta que a etapa de investigação é o principal reservatório da cultura inquisitiva. ${ }^{63}$

\section{CONCLUSÕES}

É impossível dissociar o fenômeno processual penal do plexo de fatores que o permeiam e, consequentemente, o afetam, direta ou indiretamente. Entre eles, os reflexos políticos, nomeadamente de uma

62 SCARANCE FERNANDES, Antonio. Teoria geral do procedimento e o procedimento no processo penal. São Paulo: Revista dos Tribunais, 2005, pp. 165-166.

63 BINDER, Alberto M. La justicia penal en la transición a la democracia en América Latina, In: BINDER, Alberto M. Política Criminal de la formulación a la praxis. Buenos Aires: AD-HOC S.R.L., 1997. Cap. XII, p.195-216, pp. 214215 (tradução livre). 
política processual atrelada a uma política criminal de cariz autoritário, dotam-no da característica de "termômetro democrático", proporcionando a afirmação de que é notório um déficit deste jaez quando observamos nossa law in action.

A cultura inquisitorial que compõe nossa matriz processual se mostrou resistente ao decurso do tempo, tendo sido fortificada pelas fases ditatoriais e longe de serem expurgadas pelo processo de redemocratização, aparentemente nunca completo. Nessa senda, mudar redações de leis se mostrou uma estratégia estéril para a superação do problema em questão, sendo necessária uma retomada da plenitude de sentido dos preceitos acusatórios básicos que nosso modelo conclama, mas que operam apenas em um registro epidérmico.

Assim, a oralidade foi trazida à tona para desvelarmos o engodo que permeia sua prática, divorciada da imediação judicial e blindada ao direito ao confronto, tendo como consequência a preservação do protagonismo do inquérito na fase processual. Torna-se imprescindível, então, alcançarmos uma oralidade em sentido forte, ou seja, alinhada com a imediação, de modo que a dinâmica processual possa ser essencialmente dialética, restabelecendo o contraditório e restituindo, ainda que parcialmente, valores que cooperariam para a estruturação da democracia do Estado brasileiro.

\section{REFERÊNCIAS}

AMARAL, Augusto Jobim do. Política da prova e cultura punitiva: a governabilidade do processo penal brasileiro contemporâneo. São Paulo: Almedina, 2014.

AMARAL, Augusto Jobim do e ROSA, Alexandre Morais da. Cultura da Punição: a ostentação do horror. Rio de Janeiro: Lumen Juris, 2014.

BADARÓ, Gustavo Henrique. O valor probatório do inquérito policial. In: VASCONCELOS, Eneas Romero de; MALRINO, Ezequiel; AMBOS, Kai. Polícia e investigação no Brasil. $1^{\mathrm{a}}$ ed. Brasília: Gazeta Jurídica, 2016.

BATISTA, Nilo. Matrizes ibéricas do sistema penal brasileiro. Rio de Janeiro: Revan: ICC, 2002, v. I.

BINDER, Alberto M. Introdução ao Direito Processual Penal. Rio de Janeiro: Lumen Juris, 2003. 
BINDER, Alberto M. La justicia penal en la transición a la democracia en América Latina, In: BINDER, Alberto M. Política Criminal de la formulación a la praxis. Buenos Aires: AD-HOC S.R.L., 1997. Cap. XII, p. 195-216.

BINDER, Alberto M. La fuerza de la Inquisición y la debilidad de la República. Política Criminal Bonaerense, n. 1, 2003.

BINDER, Alberto M. La justicia penal en la transición a la democracia em américa latina. Alicante: Biblioteca Virtual Miguel de Cervantes, 2005.

BETTIOL, Giuseppe; BETTIOL, Rodolfo. Istituzioni di diritto e procedura penale. $7^{\mathrm{a}}$ ed. Pádua: CEDAM, 2000.

BOVINO, Alberto. Problemas del derecho procesal penal contemporáneo. Buenos Aires: Editores del Puerto, 1998.

CAPPELLETTI, Mauro. O valor atual do princípio da oralidade. Revista da Faculdade de Direito da UFRGS, Porto Alegre, 2002, v. 21, p. 255-260, mar. 2002.

CASARA, Rubens R. R. Mitologia processual penal. São Paulo: Saraiva, 2015.

CHOUKR, Fauzi Hassan. Garantias constitucionais na investigação criminal. Rio de Janeiro: Lumen Juris, 2006.

COUTINHO, Jacinto Nelson de Miranda. Sistema Acusatório - Cada parte no lugar constitucionalmente demarcado. Revista de informação legislativa, Brasília, v. $46, \mathrm{n}^{\mathrm{o}} 183$, p. 103-115, jul./set. de 2009.

DELEUZE, Gilles; GUATTARI, Felix. Rizoma: introducción. Trad. José Vásquez Pérez e Umbelina Larraceleta. Valencia: Pre-textos, 2013.

DEMERICAN, Pedro H. A oralidade no processo penal brasileiro. São Paulo: Atlas, 1999.

ESTRAMPES, Manuel Miranda. La prueba en los procesos penales acusatorios latinoamericanos, Actualidad Judicial. Revista del Poder Judicial del Estado de Zacatecas, núm.1, 2007.

FENOLL, Jordi Nieva. Los problemas de la oralidad. Revista do Ministério Público do Rio Grande do Sul, Porto Alegre, n. 67, p. 237-257, set./dez., 2010.

FERRAJOLI, Luigi. Justicia penal y democracia. Jueces para la democracia, Madrid, n. 4, set. 1988.

FERRUA, Paolo. Gênese da reforma constitucional do "giusto processo" na Itália. Revista Brasileira de Direito Processual Penal, Porto Alegre, vol. 3, n. 2, p. 661-688, mai./ago. 2017. https://doi.org/10.22197/rbdpp.v3i2.61

FIGUEIREDO DIAS, Jorge. Direito processual penal. v. 1. Coimbra: Coimbra, 1974. 
GIMENO SENDRA, Vicente. Derecho Procesal, t. II, vol. I. Valencia: Tirant lo Blanch, 1987.

GIMENO SENDRA, Vicente. Prólogo. In: GONZALES-CUELLAR SERRANO, Nicolas. Proporcionalidad y Derechos Fundamentales en el Proceso Penal. Madrid: Colex, 1990.

GLOECKNER, Ricardo Jacobsen. Nulidades no Processo Penal: Introdução principiológica à teoria do ato processual irregular. Salvador: Juspudivm, 2015.

GLOECKNER, Ricardo Jacobsen. Processo Penal Pós-acusatório? Ressignificações do Autoritarismo no Processo Penal. Revista EMERJ, Rio de Janeiro, v. 18, n. 67, p. 378-408, jan - fev. 2015.

GOLDSCHMIDT, James. Principios generales del proceso: problemas jurídicos y políticos del proceso penal. vol. II. Buenos Aires: Ediciones Jurídicas EuropaAmérica, 1961.

GOMES, Décio Alonso. Prova e imediação no processo penal. Salvador: Juspodivm, 2016.

GOMES FILHO, Antonio Magalhães. Direito à Prova no Processo Penal. São Paulo: Revista dos Tribunais, 1997.

GONZÁLEZ ALVAREZ, Daniel. La oralidad como facilitadora de los fines, principios y garantías del proceso penal. Revista de Ciencias Penales, $\mathrm{n}^{\circ} 11$, Año 8, julio 1996.

GONZÁLEZ ALVAREZ, Daniel. La prueba en los procesos penales centroamericanos (Guatemala, El Salvador, Costa Rica. Revista de la Asociación de Ciencias Penales de Costa Rica, n. 17, marzo 2000.

IBAÑEZ, Perfecto Andrés. Sobre el valor de la inmediación (Una aproximación crítica). Jueces para la democracia, n. 46, p. 57-66, 2003.

LOPES JUNIOR, Aury. Fundamentos do Processo Penal - Introdução Crítica. São Paulo: Saraiva, 2016.

LOPES JUNIOR, Aury. Sistemas de Investigação Preliminar no Processo Penal. 1. ed. Rio de Janeiro: Lumen Juris, 2001.

LUHMANN, Niklas. O direito da sociedade. Trad. Saulo Krieger. São Paulo: Martins Fontes, 2016.

MAIER, Julio B. J. Derecho procesal penal. Tomo I: fundamentos. Buenos Aires: Del Puerto, 2006.

MAIER, Julio B. J. Situación de la justicia penal y problemas de los sistemas escritos. Revista de la Asociación de Ciencias Penales de Costa Rica, junio 1991, $\mathrm{n}^{\mathrm{o}} 4$. 
MALAN, Diogo Rudge. Direito ao confronto no processo penal. Rio de Janeiro: Lumen Juris, 2009.

MALAN, Diogo Rudge. Ideologia política de Francisco Campos: Influência na legislação processual brasileira (1937-1941), in: MALAN, Diogo Rudge; PRADO, Geraldo (orgs.). Autoritarismo e processo penal, Rio de Janeiro: Lumen Juris, 2015.

MARINHO MARQUES, Leonardo. O princípio da oralidade como componente racional de gestão democrática do processo penal. Revista da Escola Nacional da Magistratura, Brasília, ano 06, n. 06, p. 506-520, 2012.

MARTINS, Rui Cunha. O Ponto Cego do Direito: The Brazilian Lessons. $3^{\mathrm{a}}$ ed. São Paulo: Atlas, 2013.

MASSA, Michele. Contributo all'analisi del giudizio penale di primo grado. Milano: Giuffrè, 1976.

MAYA, André Machado. A oralidade como técnica de redução das práticas autoritárias no processo penal. Porto Alegre: PUCRS, 2015. 329 f. Tese (Doutorado em Ciências Criminais) - Programa de Pós-Graduação em Ciências Criminais, Faculdade de Direito, PUCRS, 2015.

MELCHIOR, Antonio Pedro. O juiz e a prova: o sinthoma político do processo penal. Curitiba: Juruá, 2013.

MELCHIOR, Antonio Pedro. Os movimentos de reforma do Código de Processo Criminal brasileiro. In: GOLZÁLEZ, L. (Dir.). Desafiando a Inquisição: Ideias e propostas para a Reforma Processual Penal no Brasil. Santiago: CEJA, 2017.

MONTERO AROCA, Juan. Principios del proceso penal: una explicación basada en la razón. Valencia: Tirant lo Blanch, 1997.

MONTERO AROCA, Juan. El principio acusatorio entendido como eslogan político. Revista Brasileira de Direito Processual Penal, Porto Alegre, vol. 1, n. 1, p. 66-87, 2015. https://doi.org/10.22197/rbdpp.v1i1.4

MORA MORA, Luis Paulino. La prueba en el Codigo Procesal Penal Tipo para America Latina. Revista de la Asociación de Ciencias Penales de Costa Rica, junio 1992, n. 5 .

NUNES, Leandro Gornicki. Sistema Processual Penal adversarial: entre a democratização e o eficientismo penal. In: GOLZÁLEZ, L. (Dir.). Desafiando a Inquisição: Ideias e propostas para a Reforma Processual Penal no Brasil. Santiago: CEJA, 2017.

PRADO, Geraldo. Sistema Acusatório. 2. ed. Rio de Janeiro: Lumen Juris, 2001.

SCARANCE FERNANDES, Antonio. Teoria geral do procedimento e o procedimento no processo penal. São Paulo: Revista dos Tribunais, 2005. 
SCHUNEMANN, Bernd. Audiência de instrução e julgamento: modelo inquisitorial ou adverarial? Sobre a estrutura fundamental do processo penal no $3^{\circ}$ milênio. In: GRECO, Luís (org.). Estudos de direito penal, direito processual penal e filosofia do direito. São Paulo: Marcial Pons, 2013.

SCHUNEMANN, Bernd. La Reforma del Proceso Penal. Madrid: Dykinson, 2005.

STRECK, Lênio Luiz; OLIVEIRA, Rafael Tomaz de. O que é isto? - as garantias processuais penais? Porto Alegre: Livraria do Advogado Editora, 2012.

TONINI, Paolo. A prova no processo penal italiano. São Paulo: Revista dos Tribunais, 2002.

WARAT, Luiz Alberto. O senso comum teórico dos juristas. Disponível em: <http://casadewaratportoalegre.blogspot.com.br/2011/04/o-senso-comumteorico-dos-juristas-luiz.html>. Acesso em: 23 out. 2016.

\section{Informações adicionais e declarações dos autores (integridade científica)}

Declaração de conflito de interesses (conflict of interest declaration): os autores confirmam que não há conflitos de interesse na realização das pesquisas expostas e na redação deste artigo.

Declaração de coautoria e especificação das contribuições (declaration of authorship): todas e somente as pessoas que atendem os requisitos de autoria deste artigo estão listadas como autores; todos os coautores se responsabilizam integralmente por este trabalho em sua totalidade.

- André Rocha Sampaio: projeto e esboço inicial, revisão bibliográfica, redação, revisão crítica com contribuições substanciais, aprovação da versão final.

- Marcos Eugênio Vieira Melo: projeto e esboço inicial, levantamento bibliográfico, redação, aprovação da versão final.

Declaração de ineditismo e originalidade (declaration of originality): os autores asseguram que o texto aqui publicado não foi divulgado anteriormente em outro meio e que futura republicação somente se realizará com a indicação expressa da referência desta publicação original; também atestam que não há plágio de terceiros ou autoplágio. 
Dados do processo editorial

(http://www.ibraspp.com.br/revista/index.php/RBDPP/about/editorialPolicies)

- Recebido em: 31/07/2017

Equipe editorial envolvida

- Controle preliminar e verificação de plágio: 01/08/2017

- Avaliação 1: 10/08/2017

- Avaliação 2: 10/08/2017

- Editor-chefe: 1 (VGV)

- Editora-associada: 1 (FMB)

- Revisores: 3

- Avaliação 3: 14/08/2017

- Decisão editorial preliminar: 16/08/2017

- Retorno rodada de correções: 30/08/2017

- Decisão editorial final: 30/08/2017

\section{COMO CITAR ESTE ARTIGO:}

SAMPAIO, André R.; MELO, Marcos Eugênio V. Cultura Inquisitória e as Falsas Oralidades. Revista Brasileira de Direito Processual Penal, Porto Alegre, vol. 3, n. 3, p. 879-905, set./dez. 2017. https://doi.org/10.22197/rbdpp.v3i3.95

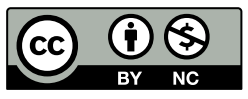

Esta obra está licenciada com uma Licença Creative Commons Atribuição-NãoComercial 4.0 Internacional. 